\title{
Origin of megacrysts in granitoids by textural coarsening: a crystal size distribution (CSD) study of microcline in the Cathedral Peak Granodiorite, Sierra Nevada, California
}

\author{
MICHAEL D. HIGGINS \\ Sciences de la Terre, Université du Québec à Chicoutimi, Chicoutimi, G7H 2B1, Canada \\ (e-mail:mhiggins@)uqac.uquebec.ca)
}

\begin{abstract}
Microcline megacrysts in the Cathedral Peak Granodiorite and other parts of the Tuolumne Intrusive Suite were formed by textural coarsening (Ostwald Ripening) of earlier formed crystals. The early-formed crystals nucleated and grew in an environment of increasing undercooling, probably during the ascent of the magma. Emplacement of the magma into warm host rocks promoted textural coarsening. Crystals smaller than a certain size (the critical size) dissolved in the interstitial melt whilst larger crystals grew. Microcline was most sensitive to this effect as the magma temperature was buffered close to its liquidus for a long period by the release of latent heat of crystallization. Positive feedback between textural coarsening and magma permeability channelled the flow of interstitial melt to produce a heterogeneous distribution of megacrysts. Megacryst growth was halted when cooling resumed at the end of the intrusive cycle. K-feldspar nucleation was then renewed and $\mathrm{K}$-feldspar crystals grew to form part of the groundmass. It was the particular thermal history of this pluton that promoted textural coarsening-chemically similar plutons that lack megacrysts probably did not have the pause during cooling that was necessary for the development of this texture.
\end{abstract}

Euhedral K-feldspar megacrysts up to $20 \mathrm{~cm}$ long are a striking and relatively common component of many granitoid plutons, but their origin is still controversial. Vernon (1986) reviewed the subject and found the consensus to be that megacrysts are igneous in origin, that is, they grew from a granitic melt and are phenocrysts. However, he noted that there was a minority view that megacrysts are post-magmatic and grew from a circulating water-dominated fluid. An extreme version of this hypothesis proposes that such granites are entirely metasomatic (granitization).

A magmatic origin is supported by many features, such as crystal shape, crystal fabric, chemical composition, zonation and inclusions (Vernon 1986). The low population density of the megacrysts has been ascribed by Vernon (1986) and others to 'nucleation difficulties', which delay nucleation until the temperature is close to the solidus. It is necessary to discuss briefly experimental work relevant to this problem.

The experimental studies of Swanson (1977) were launched by the commonly held belief that the textures of granites are controlled by patterns of nucleation and growth of phases, an idea that will be shown later to be partly incorrect.
Swanson (1977) and Fenn (1977) measured the nucleation and growth rates of plagioclase, $\mathrm{K}$-feldspar and quartz crystallizing from glassy charges during geologically rapid cooling. Fenn (1977) found that there was a significant time delay between the cooling of the charge below the liquidus and the appearance of the crystals of $\mathrm{K}$-feldspar that he termed the incubation period'. This is the effect referred to by the term 'nucleation difficulties'. This effect may be important for volcanic rocks, but cannot be important for slowly-cooled plutonic rocks. Textural evidence from rocks also negates this idea. Plagioclase commonly crystallizes before K-feldspar (Naney 1983) and K-feldspar can overgrow plagioclase (anti-rapakivi texture), hence nucleation of K-feldspar cannot be a problem. Therefore, the low population density of K-feldspar megacrysts should not be ascribed to nucleation difficulties. It will be shown later that this problem can be resolved if the nucleation density is distinguished from the final population density of the megacrysts. That is, that there has been resorbtion of many K-feldspar crystals.

A metasomatic origin for the megacrysts has been suggested by some authors because of their 
occurrence, albeit rarely, in more mafic enclaves, country rocks and cutting across the borders of aplite veins (see review by Vernon 1986). Dickson (1996) proposed that metasomatism may be driven by deformation. Although many occurrences can be explained by elaborations of the igneous theory, others appear to require metasomatism. The argument then runs that if some crystals are metasomatic, then all may be (Collins 1988)

Here, I propose that the dominant process forming the megacrysts is textural coarsening of earlier formed small K-feldspar crystals during which most original crystals were sacrificed to feed the growth of a select few. This process can occur in crystal-poor or crystal-rich mushes, where it is mediated by residual silicate liquids (Higgins 1998), as well as in metamorphic rocks where it is mediated by water-rich fluids (Cashman \& Ferry 1988), hence accounting for the presence of megacrysts in both granites and country rocks and reconciling the opposing theories.

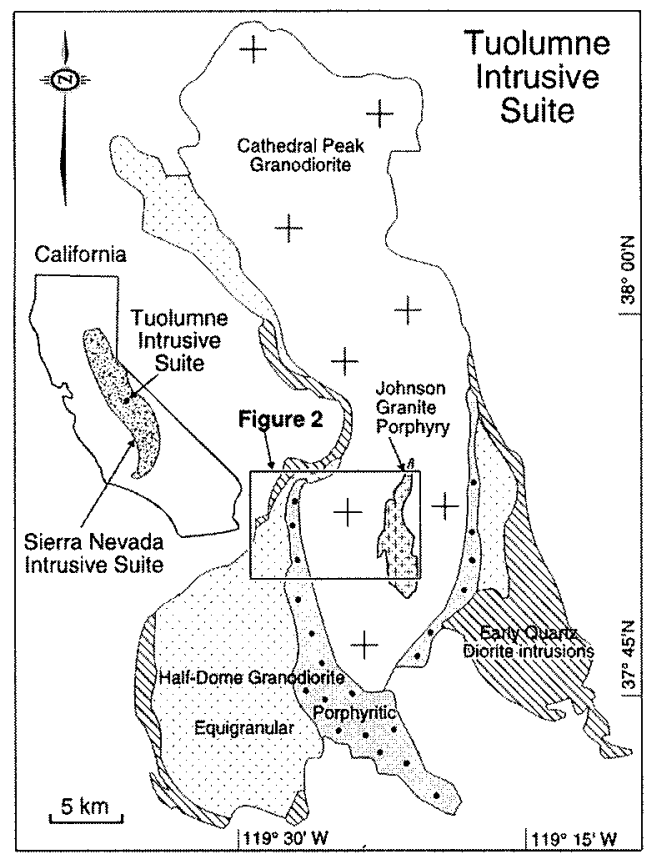

Fig. 1. Geological map of the Tuolumne Intrusive Suite, Sierra Nevada, California (after Bateman \& Chappell 1979). The quartz-diorite intrusions that form the outer parts of the intrusion were emplaced first. The Half-Dome granodiorite was subsequently intruded into the partly solidified interior of the pluton. The Cathedral Peak granodiorite followed in the same way. The final intrusion was the Johnson Creek Porphyry. There is an overall progression from mafic to felsic compositions.
Megacrysts are fundamentally a textural phenomenon, hence the approach here has been to quantify aspects of the texture that can reveal the origin of the megacrysts. The crystal-size distribution method (CSD) has been applied to some volcanic and plutonic rocks (e.g. Cashman 1990), but it has not yet been applied in many published granite studies.

\section{The Cathedral Peak Granodiorite}

The Cathedral Peak Granodiorite (CPG) is the most voluminous part of the concentrically zoned Tuolumne Intrusive Suite, in the Sierra Nevada of California (Figs 1, 2; Bateman \& Chappell 1979). The intrusion of this suite commenced with the emplacement of quartzdioritic magma, which is still preserved in the periphery of the suite. This magma started to crystallize on the walls, but before solidification was complete new, more felsic, magma was introduced into the centre of the pluton. It eroded parts of the solidified diorite and expanded the chamber to the northwest. This new unit again started to crystallize from the walls inwards, first with an equigranular texture, and later as a porphyritic rock, with K-feldspar megacrysts. Parts of this unit are preserved as the Half Dome Granodiorite. Again, complete solidification was interrupted by the emplacement of new magma, the Cathedral Peak Granodiorite. As before this process led to the erosion of parts of the earlier units and expansion of the chamber to the north. The final unit, the Johnson Granite Porphyry, must have been

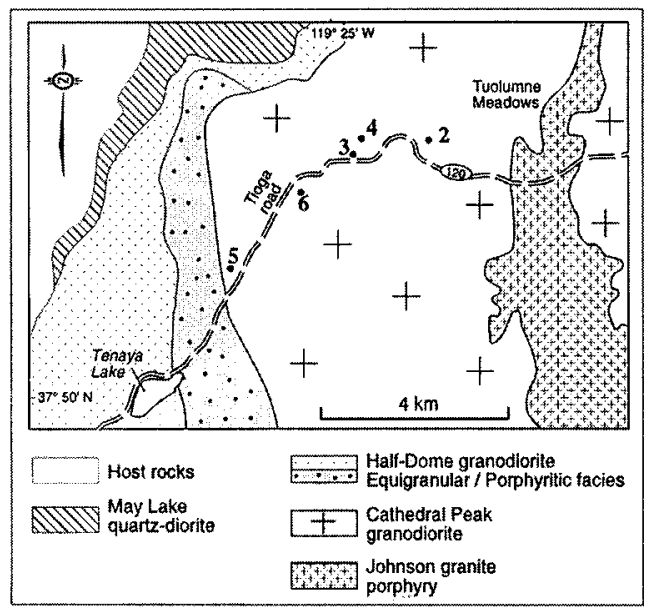

Fig. 2. Detail of Fig. 1. Geological map of the Tuolumne Intrusive Suite near Tuolumne Meadows along route 120 (after Bateman \& Chappell 1979). Numbers refer to sample sites. 
emplaced when the CPG was almost completely solid as the contacts are sharp. Bateman \& Chappell (1979) considered that this unit was sub-volcanic on the basis of the porphyritic texture, the fine-grained mesostasis and the broken nature of many crystals. The overall progression of the suite is from more mafic to more felsic magmas. All units of this suite are fresh and almost completely undeformed in the solid-state.

An important component of the Cathedral Peak Granodiorite, adjacent parts of the HalfDome Granodiorite and the Johnson Granite Porphyry is K-feldspar megacrysts. They are most abundant in the Cathedral Peak Granodiorite where they vary from an overall mode of $10 \%$ near the outer edge to $2 \%$ near the inner border. Bateman \& Chappell (1979) considered that the modal variation in the megacrysts was balanced by changes in the $\mathrm{K}$-feldspar mode of the matrix, and hence that the overall quantity of $\mathrm{K}$-feldspar in the rock remains constant at about $20 \%$.

The megacrysts are distributed heterogeneously with high concentrations in 'nests'
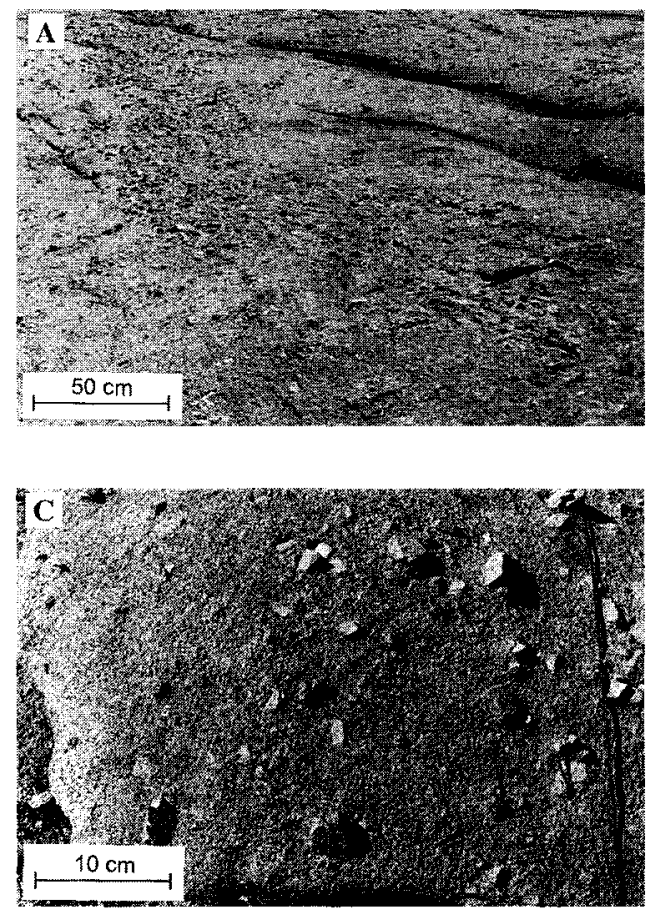

and linear zones up to a meter wide that meander for tens of metres across the outcrop (Fig. 3a, b, c). The distribution of these megacryst-rich areas is similar in both vertical and horizontal sections. A brief reflection will confirm that all threedimensional sheets have linear intersections with surfaces, whereas string-like forms have point intersections. Therefore, the observed distributions of the megacrysts on the outcrop surfaces suggests that the volumes rich in megacrysts have sheet and string-like forms in three dimensions.

The megacrysts are composed of microcline. The mean of 200 analyses was $\mathrm{Or}_{88}$ but individual analyses varied from $\mathrm{Or}_{97}$ to $\mathrm{Or}_{76}$ (Kerrick 1969). The crystals contain subhedral plagioclase as included grains and exsolved patches (mean composition $\mathrm{An}_{33}$; Kerrick 1969). The wide range in composition of the megacrysts and the included plagioclase preclude the use of a two-feldspar geothermometer. Subhedral hornblende, minor biotite and rare quartz are also present. Included minerals are commonly concentrated into euhedral-shaped concentric zones (Fig. 3d). Many of the megacrysts have Carlsbad twinning.
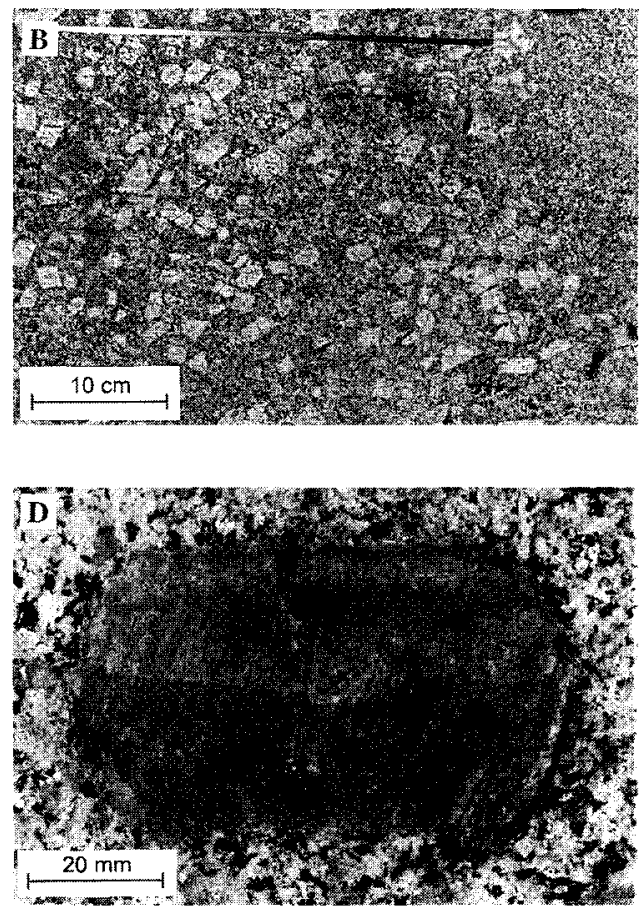

Fig. 3. (a) Weathered outcrop of the Cathedral Peak Granodiorite, showing the heterogeneous distribution of the microcline megacrysts. Megacryst-rich areas tend to be linear or in patches ("nests'), with similar patterns in both horizontal and vertical sections. (b) 'Nest' of megacrysts on glacially polished surface. (c) Diffuse megacrysts on an eroded surface. (d) Single megacryst exposed on a glacially polished surface. Inclusions of amphibole in the crystal are concentrated in euhedral zones. Plagioclase is not visible in this photograph. The matrix is slightly enriched in mafic minerals near the crystal. 


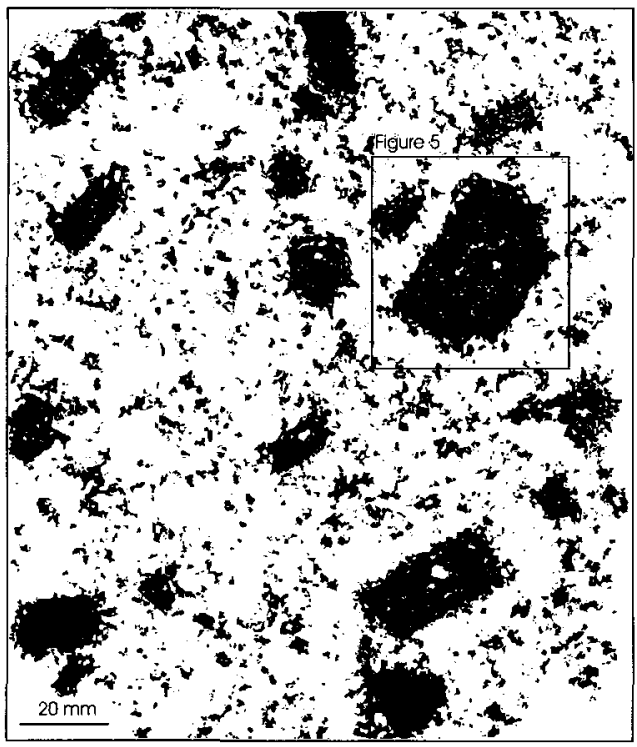

Fig. 4. Distribution of microcline in a slab from near sample site 6 . A sawn surface was stained with sodium cobaltinitrate (Hutchison 1974), then scanned at 10 lines per millimetre and the orange colour of the microcline digitally extracted. Other minerals have been omitted for clarity.

The shape of the megacrysts varies with their size. Large megacrysts are euhedral (Fig. 3b, c, d) with an aspect ratio of $1: 1.6: 2.6$, as measured from the dimensions of weathered-out crystals. The surfaces of the megacrysts are rough and slabs stained with sodium cobaltinitrate (Hutchison 1974) reveal that there are sinuous extensions of microcline from the megacrysts into the groundmass (Figs 4, 5). The shapes of the extensions greatly resemble those of microcline in the groundmass and they may have grown at the same time. Smaller crystals are more rounded, but with the same extensions as the larger crystals. The smallest megacrysts are just clots of microcline in the groundmass. The groundmass is richer in mafic minerals and poorer in K-feldspar adjacent to the edges of some of the megacrysts. The megacrysts in the CPG resemble K-feldspar megacrysts in other granitoids, hence a general explanation for their origin must be found (Vernon 1986).

The groundmass is dominated by rounded crystals of quartz and plagioclase up to $10 \mathrm{~mm}$ long (cores typically $\mathrm{An}_{35}$; Kerrick 1969). Microcline (typically $\mathrm{Or}_{88}$ ) occurs as small anhedral crystals interstitial to the quartz and plagioclase (Figs 4, 5). Biotite and hornblende are also interstitial and are much finer than the other phases. Here, biotite is more abundant than hornblende.

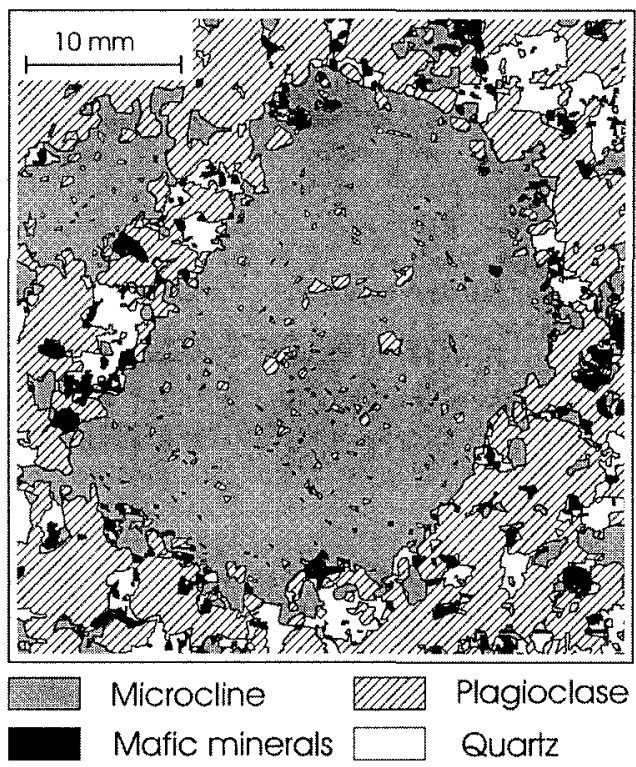

Fig. 5. Detail of a megacryst and adjacent groundmass from Fig. 4. All mineral species were separated on the basis of their colour values in the stained slab. Intergranular areas could not always be successfully identified and have been included with quartz.

Although both the megacrysts and the groundmass microcline have similar $\mathrm{K} / \mathrm{Na}$ ratios their $\mathrm{Ba}$ contents are very different. Kerrick (1969) found celsian contents of $1-2 \%$ in the megacrysts, but only $0.25 \%$ or less in the groundmass microcline. $\mathrm{He}$ also found a Ba-poor rim on one megacryst, but it is not clear if it is one of the extensions into the groundmass or a euhedral zone. Similarly, the obliquity of the microcline in the groundmass was two to three times that of adjacent megacrysts, although both were very variable. Kerrick (1969) concluded from the obliquity that the megacrysts crystallized at higher temperatures than the groundmass microcline.

\section{Quantitative textural measurements}

Observations of textures are a fundamental part of igneous petrology, but the quantification of these textures necessary to model petrogenetic processes is still rarely applied (see review in Cashman 1990). The goal of this study is to understand the genesis of the megacrysts, but the groundmass microcline cannot be neglected. Differences in scale between the two populations of crystals necessitates two different quantification techniques: the megacrysts were studied in the field and the groundmass crystals in stained slabs up to $15 \mathrm{~cm}$ long. 
Megacrysts were studied quantitatively in the Cathedral Peak Granodiorite component of the suite because they are such an important component, but it should not be forgotten that megacrysts also occur in the other components. Five outcrops located across the width of the Cathedral Peak Granodiorite were measured (Fig. 2). Some outcrops still had their glacial polish, but in others weathering has produced a knobby surface defined by the megacrysts (Fig. 3). Several of the analysed areas had 'nests' of megacrysts, whereas others were more uniform with a lower population density. Megacrysts were recognized by their euhedral shape. All visible megacrysts were measured using a ruler, but the smaller megacrysts were not so euhedral as the larger ones and hence more difficult to distinguish from the groundmass. This measurement technique gives the dimensions of the euhedral part of the megacrysts and ignores the winding crystal extensions (Fig. 5). All these effects mean that this technique is more reliable for the larger crystals. The smallest crystal that could be measured was estimated to be $10 \mathrm{~mm}$ long. Areas measured ranged from 0.25 to $0.8 \mathrm{~m}^{2}$ (Table 1 ).

Three slabs were sampled from loose material in road-cuts near the studied outcrops. The slabs were sawn, stained with sodium cobaltinitrate (Hutchison 1974) and optically scanned to form a digital image. Microcline was distinguished from other minerals in the images using colour values and the dimensions of the crystals were determined using PCImage (a version of NIH Image, a program developed at the US National Institutes of Health). It is not possible to separate touching crystals with this technique, hence there is a bias towards larger sizes than are actually present. This effect is compounded for large crystals that necessarily have faces closer to each other than smaller crystals. Therefore, this technique is more reliable for smaller crystals. Minimum measurable crystal size was $1 \mathrm{~mm}$. Larger, more euhedral crystals are clearly megacrysts, hence crystals longer than $10 \mathrm{~mm}$ were excluded from the analysis so that the data could be compared with that gathered from the outcrops (Figs 4, 5).

The data obtained from the study of the outcrops and the slabs pertain only to the length of the intersections in two dimensions. These data must be converted to true three dimensional CSD before they can be interpreted. This conversion is not simple and is treated in the branch of mathematics called stereology (Royet 1991). Two aspects of the problem are important here: the intersection probability effect and the cut section effect. The first is simply that smaller crystals are less likely to be intersected by a plane than larger crystals. This can be compensated if the number of crystals per unit area in a size interval is divided by the mean size of the interval. The second effect is that a plane is unlikely to pass exactly through the centre of a crystal in the direction of the largest section. The nature of the fabric and its quality and orientation, as well as the section orientation with respect to the fabric and crystal shape, must be known to make these conversions. However, approximate values are adequate as the result is not very sensitive to these effects.

The interactive program CSDCorrections was used to do the stereological conversions (Higgins in prep.). The observed fabric of the megacrysts and matrix is not sufficient to make a significant difference to the CSDs, hence the rock was

Table 1. Numbers of microcline crystals and areas measured on outcrops and slabs

\begin{tabular}{|c|c|c|c|c|c|c|c|c|}
\hline \multirow[b]{2}{*}{$\begin{array}{l}\text { Upper limit of size } \\
\text { category }(\mathrm{mm})\end{array}$} & \multicolumn{5}{|c|}{ Outcrops: megacrysts } & \multicolumn{3}{|c|}{ Slabs: groundmass } \\
\hline & $\begin{array}{l}\text { O-2 } \\
\text { Diffuse } \\
\text { with nests }\end{array}$ & $\begin{array}{l}\text { O-3 } \\
\text { Nests }\end{array}$ & $\begin{array}{l}\text { O-4 } \\
\text { Diffuse }\end{array}$ & $\begin{array}{l}\text { O-5 } \\
\text { Diffuse }\end{array}$ & $\begin{array}{l}\text { O-6 } \\
\text { Nests }\end{array}$ & S-3 & S-4 & S-6 \\
\hline $1-1.8$ & & & & & & 85 & 76 & 156 \\
\hline 3.2 & & & & & & 43 & 88 & 131 \\
\hline 5.6 & & & & & & 31 & 41 & 71 \\
\hline 10.0 & & & & & & 8 & 4 & 32 \\
\hline 17.8 & 24 & 16 & 20 & 33 & 29 & & & 5 \\
\hline 31.6 & 54 & 72 & 53 & 68 & 91 & & & 10 \\
\hline 56.2 & 32 & 28 & 19 & 25 & 39 & & & \\
\hline 100 & 10 & 3 & 2 & 7 & 9 & & & \\
\hline Largest grain (mm) & 97 & 70 & 62 & 80 & 75 & & & \\
\hline Area measured $\left(\mathrm{mm}^{2}\right)$ & 500000 & 250000 & 500000 & 800000 & 500000 & 4800 & 4800 & 27000 \\
\hline Crystal content $(\%)$ & 15 & 24 & 8 & 9 & 19 & 28 & 12 & 14 \\
\hline
\end{tabular}

The crystal content of the slabs includes both the groundmass and the megacrysts. 


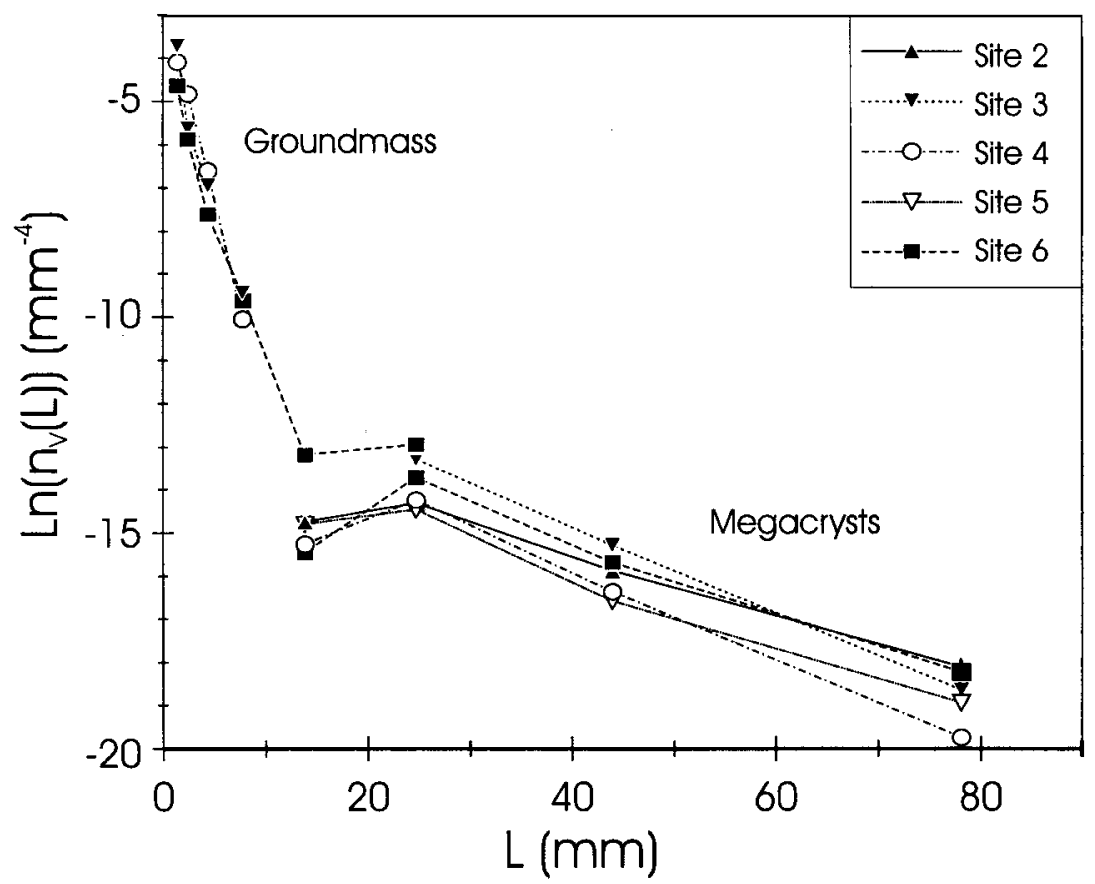

Fig. 6. Crystal size distributions of microcline crystals. The vertical axis is the natural logarithm of the population density for crystal size $L, n_{V}(L)$. It is the number of crystals per unit volume divided by the size interval. Hence, it has the dimensions of $\mathrm{mm}^{-4}$. Crystal size, $L$, is the mean projected height of crystals, which is close to the intermediate dimension of parallelepipeds with similar aspect ratios to the crystals. Data were reduced using the program CSDCorrections (Higgins in prep.). Megacrysts from five outcrops were measured in the field with a ruler. Dimensions of microcline crystals in the slab seen in Fig. 4 and other slabs were determined by automatic image analysis. Open symbols are for areas with diffuse megacrysts, whereas solid symbols are for sites with 'nests' of megacrysts.

assumed to be massive. The shape of the megacrysts is easily established from separated crystals. However, the microcline in the groundmass is commonly interstitial to quartz and plagioclase and hence is more difficult to determine. For the sake of simplicity it is assumed to be the same as that of the megacrysts.

The data were plotted on a diagram of $\mathrm{Ln}$ (population density) versus crystal size, hereafter called a crystal size distribution (CSD) diagram (Fig. 6; Marsh 1988). The population density is the number of crystals per unit volume within a certain size range divided by the width of the size range. This division is necessary so that the population density does not change with the width of the size interval. The units of population density are $\mathrm{mm}^{-4}$. Logarithmic size intervals were used, with each bin $10^{0.25}$ larger than the previous bin. There were no empty bins within the CSDs, that is intervals with no crystals. There are several sources of error in this diagram, but the most important are probably that due to counting statistics for larger crystals and for the tailing corrections in the case of the smaller crystals. However, the logarithmic vertical scale of this diagram, and the wide size bins, ensures that the errors are not significant.

The CSD data from the Cathedral Peak Granodiorite are presented in Fig. 6. Somewhat surprisingly the CSDs of both the 'nests' of megacrysts and the diffuse areas have similar shapes, but the nests have higher overall population densities for all crystal sizes that the diffuse areas. All CSDs have a peak at $25 \mathrm{~mm}$. The smallest megacryst that could be reliably measured was $10 \mathrm{~mm}$, hence the turn-down of the population density to the left of the peak is not an artifact. If the CSDs were straight down to $10 \mathrm{~mm}$ then the population density at $10 \mathrm{~mm}$ would have been 10 to 50 times higher, which is readily distinguishable from the actual data. The limb to the right of the peak is generally straight.

The CSDs of the groundmass microcline are quite different from those of the megacrysts (Fig. 6). All three CSDs are quite straight, right down to the smallest crystal that could be 
measured $(1 \mathrm{~mm})$ and much steeper than those of the megacrysts. One slab was sufficiently large that the abundance of smaller megacrysts could be determined, although the small numbers of large crystals did not give a high precision. The consistency of the two methods is confirmed by the overlap of the CSDs.

The CSD data of different samples are difficult to distinguish on a conventional CSD diagram (Fig. 6), hence the data have been transformed. The right side of the CSD was regressed to give the slope and intercept. The slope was then transformed into the characteristic length by the equation (Marsh 1998):

$$
\text { characteristic length }=-1 / \text { slope. }
$$

The characteristic length has the units of length ( $\mathrm{mm}$ in this case), but does not have a physical meaning for most systems.

Figure 7a shows a plot of characteristic length versus intercept for microcline crystals. The fields of the megacrysts and groundmass microcline are quite different. Both groups of data have negative correlations between characteristic length and intercept, but only that of the megacrysts can be interpreted as significant $\left(r^{2}=0.61\right.$ for 3 degrees of freedom) as there are not enough groundmass samples. The megacryst samples from the nests lie to the right of the diffuse area samples, suggesting that the overall megacryst mode in the sample may be important.

The CSDs can easily be corrected for modal variations. The population density, $n_{V}(L)$, is normally calculated from

$$
n_{V}(L)=\frac{n}{v\left(L_{2}-L_{1}\right)}
$$

where $n=$ number of crystals in size interval, $v=$ volume and $L_{2}-L_{1}=$ size interval. However, in this case we are interested in the phase population density, $n_{V}^{\prime}(L)$. This can be calculated from

$$
n_{\nu}^{\prime}(L)=\frac{n}{v^{\prime}\left(L_{2}-L_{1}\right)}
$$

where $v^{\prime}=$ the volume of the phase in question. The proportion of the phase, $\chi$, is defined as

$$
\chi=\frac{v^{\prime}}{v}
$$

hence

$$
n_{V}^{\prime}(L)=\frac{n_{V}(L)}{\chi}
$$

This equation applies equally to all points, so the slope will be unchanged, but the intercept will be increased by a factor of $1 / \chi$.


Fig. 7. (a) Characteristics of the right part of the CSDs of Fig. 6, expressed as Characteristic Length (-1/Slope) versus Intercept (see text). The symbols are as Fig. 6 . The megacrysts and groundmass microcline crystals fall in totally separate parts of the diagram. The distribution of the megacryst data define a negative correction. The vector for Coarsening indicates the displacements of the samples that are more $(+)$ or less $(-)$ coarsened. Openness is the amount of material added during coarsening. More open areas $(+)$ have received more material than less open $(-)$ areas. (b) The quality of the correlation can be improved dramatically if the intercept values are normalized to $100 \%$ microcline (see text). 
The correlation of the Characteristic Length and the Corrected Intercept is very strong for the megacrysts $\left(r^{2}=0.98\right.$ for 3 degrees of freedom; Fig. $7 b$ ) is very strong and will be discussed below.

\section{Discussion}

The study of crystal size distributions in rocks has been somewhat neglected in igneous petrology but similar studies in materials science are well developed. Marsh (1988) applied the work of Randolf \& Larson (1971) to igneous systems and suggested that continuous flux, steady-state crystallization in an open system of linearly increasing undercooling produced straight lines on a graph of Ln (population density) versus length (Fig. 8a). Marsh (1998) elaborated these theories for batch (closed system) crystallization. He showed that at high degrees of crystallinity the population density of small crystals is less than predicted by the simple model because of a decrease in the amount of liquid remaining, in which nucleation occurs (Fig. 8a, e). Fractional crystallization can also alter the shape of CSDs-accumulation of crystals under the influence of gravity will skew the right side of the CSD upwards (Fig. 8b, e).

The CSDs of the groundmass microcline are straight, hence could have formed by batch crystallization under conditions of linearly increasing undercooling (Fig. 6). In this case, if there was a deficiency of small crystals, then it may be concealed below the detection limit of $1 \mathrm{~mm}$. However, none of the models discussed so far are capable of producing the hump-shaped CSDs of the megacrysts with a strong correlation between characteristic length and intercept (Fig. 6).

Hump-shaped CSDs are common in metamorphic rocks (Cashman \& Ferry 1988), but can be found also in some plutonic and volcanic rocks (Boudreau 1987; Cashman \& Marsh 1988; Resmini 1993; Higgins 1998). Such CSDs can be formed by textural coarsening (also known as Ostwald ripening, annealing, textural maturation) of crystal populations (Voorhees 1992). Such coarsening occurs because small grains have a higher surface energy per unit volume than larger grains. Therefore, to minimize energy in the system crystals smaller than a certain size, termed the 'critical size', will dissolve and 'feed' the growth of larger crystals. This can only occur when a crystal is held at a temperature close to its liquidus for a long period of time. Under these conditions the nucleation rate is zero, but growth rate is high for crystals larger than the critical size. It should be noted that this does not necessarily mean that the temperature was held constant, just that the undercooling remained small. Material is transferred from one crystal to another by diffusion, hence observable coarsening can only occur if a fluid phase is present, such as residual melt. Coarsening can also occur at lower temperatures, under metamorphic conditions, where the nucleation rate is also zero and the fluid is aqueous.

Textural coarsening can occur in closed or open systems. If the system is closed then the total quantity of a phase remains constant while its mean grain-size increases. If the system is open, for example by circulation of melt through a crystal mush, then the total quantity of a phase can increase independently of the mean grain size.

Textural coarsening is an industrially important process, but the equations governing this process are still poorly defined, especially for geologically relevant conditions. Most formulations of textural coarsening are based on the Lifshitz-Slyozov-Wagner theory (Lifshitz \& Slyozov 1961). This theory assumes that all crystals communicate with a uniform medium, that is diffusion is not a limiting factor. The results of this process on a material with an initially straight CSD were examined by Higgins (1998), who showed that small grains are almost completely removed, but the slope of the CSD for large grains is almost unaffected as growth is highest for crystals just larger than the critical size (Fig. 8c). The more recent communicating neighbours (CN) theory (Dehoff 1991) is based on chemical exchange between neighbouring crystals. In this case, growth or solution of crystals is limited by diffusion. Small crystals are removed much less efficiently by this process, but the growth of crystals much larger than the critical size is favoured (Higgins 1998). The slope of right part of the CSD decreases with this process (Fig. 8d, e).

The Cathedral Peak Granodiorite CSDs show the negative correlation between slope and intercept that is predicted by the $\mathrm{CN}$ theory (Figs 6, 7, 8d, e; Dehoff 1991; Higgins 1998). Unfortunately, the left part of the CSD is swamped by the groundmass population of crystals, hence it is not clear if it descends steeply following the LSW theory or has a shallow slope in accordance with the $\mathrm{CN}$ model. The improvement in the correlation between characteristic length and intercept following normalization to $100 \%$ microcline indicates that textural coarsening here is an open process (Figs 7,8e). That is, some areas have been strongly coarsened, but with little addition of new material (e.g. outcrops 2 and 5). Hence, the 'nests' of crystals are areas 


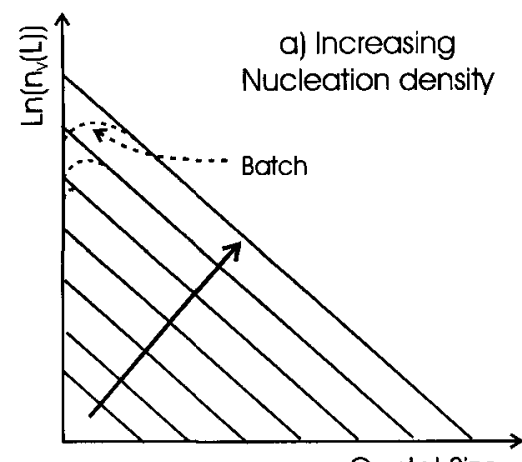

Crystal Size

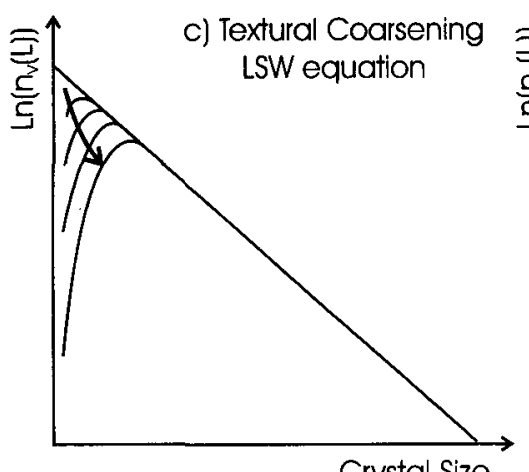

Crystal Size

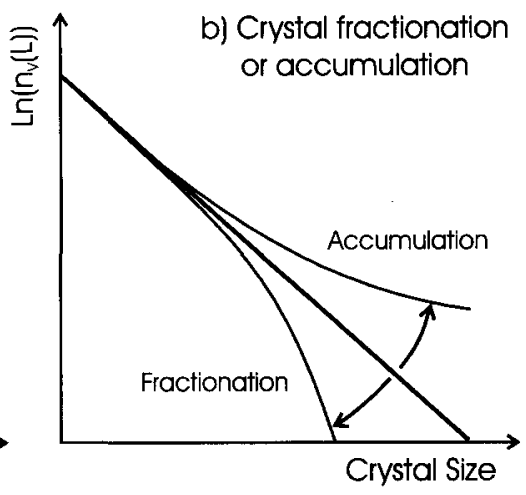

d) Textural Coarsening $\mathrm{CN}$ equation

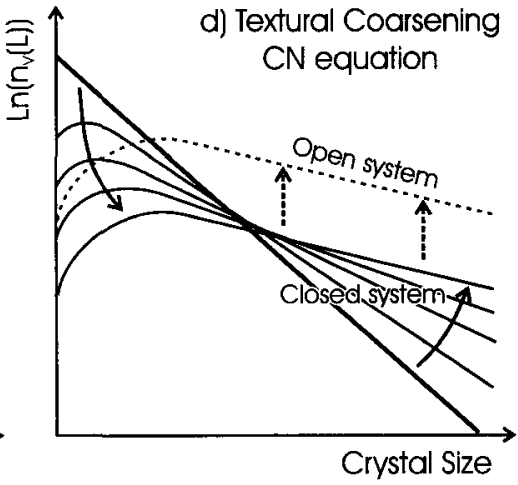

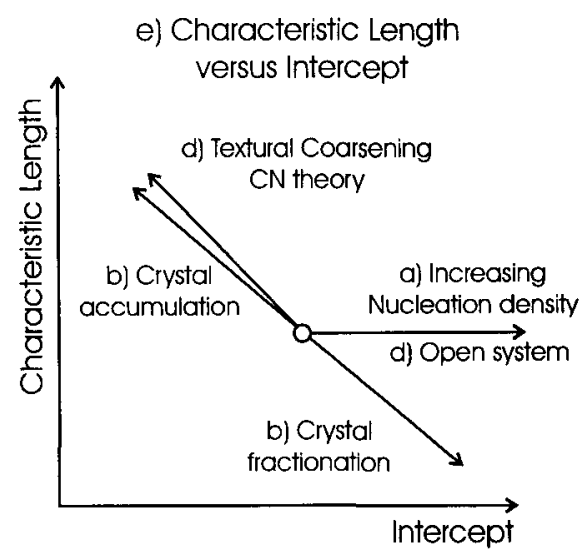

Fig. 8. Schematic crystal size distributions. (a) A straight-line distribution can be produced by continuous-flow steady-state (Marsh 1988). Batch crystallization during linearly increasing undercooling can produce a similar CSD, except that there will be a turn-down for small crystals (Marsh 1998). (b) Accumulation of crystals under the influence of gravity will favour larger grains, hence the right end of the line will be deflected upwards (Marsh 1988). (c) Textural coarsening following the LSW theory (Lifshitz \& Slyozov 1961) will augment the number of large crystals, like accumulation, but will eliminate small crystals, giving a characteristic hump-shaped CSD (Higgins 1998). (d) Textural coarsening can also follow the CN theory (Dehoff 1991). In this case small crystais will not be so deficient, but the right part of the CSD will rotate, giving a negative correlation between slope and intercept (Higgins 1998). (e) Summary of CSD models in terms of Characteristic Length versus Intercept. The LSW textural coarsening model does not change the slope of the right part of the CSD and hence does not make a vector in this diagram. 
where material has been added, but are not necessarily the most coarsened parts of the rock (e.g. outcrop 3).

\section{Solidification of the Cathedral Peak Granodiorite}

The first stage in the solidification of the Cathedral Peak Granodiorite must have been nucleation and growth of the major minerals in an environment of increasing undercooling (Fig. 9a). Cooling of the magma during emplacement cannot be the cause of the undercooling as the host rock for much of the Cathedral Peak Granodiorite is the more primitive, and hence hotter, Half-Dome Granodiorite, which was emplaced a short while before (Bateman \& Chappell 1979). If cooling and nucleation followed emplacement of all components of the Tuolumne Intrusive Suite then there should not be any difference in texture between the different components. Hence, the undercooling must be related to decreasing pressure or degassing during ascent of the magma and initial nucleation and growth of crystals must have occurred at depth. This is testified by the steeply dipping magmatic foliations in many of the Tuolumne Intrusive Suite rocks (Bateman \& Chappell 1979). The initial CSD of the K-feldspar is not accessible, but it may have resembled the CSD of the later groundmass microcline.

The second phase was initiated when the Cathedral Peak Granodiorite was emplaced into the still warm Half-Dome Granodiorite. At this time heat was unable to escape and undercooling was stalled or even decreased, both in the Cathedral Peak Granodiorite and adjacent parts of the Half-Dome Granodiorite (Fig. 9b). The temperature would have been buffered by the release of latent heat of crystallization of K-feldspar, the latest, and most abundance phase. The small undercooling of the K-feldspar would have suppressed nucleation of new crystals and promoted grain-size coarsening. Crystals smaller than the critical size dissolved in the

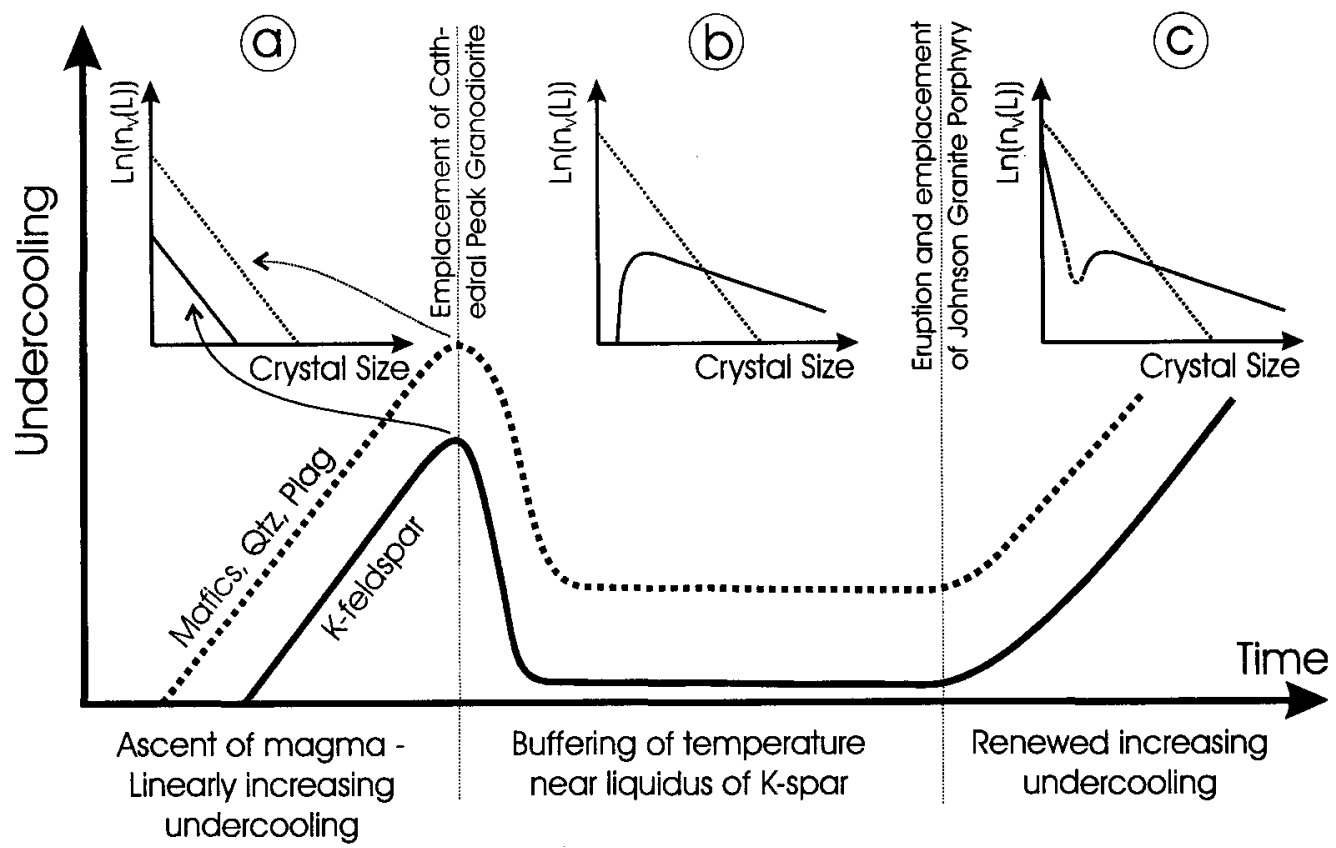

Fig. 9. Model for the development of megacrysts in the Tuolumne Intrusive Suite. (a) The initial phase was of nucleation and growth of all major phases. K-feldspar is the last major mineral to nucleate from granodioritic magmas, except at low pressures and water contents (Naney 1983). All other phases have been lumped together for clarity, but really have separate CSDs. Linearly increasing undercooling during this period produced linear CSDs. (b) Emplacement of the CPG into earlier parts of the intrusive suite stalled cooling and the temperature was buffered near the liquidus temperature of $\mathrm{K}$-feldspar. Conditions were now appropriate for textural coarsening of K-feldspar and small crystals were removed. The other phases were strongly undercooled at this time and hence did not coarsen, although crystals of all sizes continued to grow. (c) Eruption of the Johnson Creek porphyry enabled renewed undercooling and K-feldspar again nucleated and grew to form the groundmass crystals. 
interstitial magma and consequently fed larger crystals that grew to become the megacrysts. The peak of the megacryst CSDs at $25 \mathrm{~mm}$ indicates that the final critical size was close to this value. Earlier critical sizes were smaller.

When the CPG was emplaced quartz, plagioclase and mafic mineral crystals were already present. They nucleated before the K-feldspar and hence probably were larger than the $\mathrm{K}$-feldspar at this time as crystal growth rates do not appear to vary by more than a factor of 2 or 3 between different mineral species (Cashman 1990). Buffering of the temperature at the $\mathrm{K}$-feldspar liquidus kept the remaining phases much more undercooled. Maximum growth rates may have been more rapid than that of $\mathrm{K}$-feldspar, but the strong undercooling for earlierformed mineral species was not suitable for textural coarsening. New crystals of these phases crystallized instead of dissolving, hence limiting the size of these crystals. K-feldspar was not limited in this way and overtook the early phases in size, to produce the megacrysts.

Many grains of other minerals were incorporated into the growing crystals, especially those with a similar structure, such as plagioclase, for which the energy of the interface between the two minerals is low. Dissimilar grains with higher interface energy (e.g. amphiboles) were commonly swept aside to accumulate beside the megacrysts. At this point the magma would have contained large euhedral megacrysts that were growing and smaller, irregularly shaped crystals that were dissolving. A small amount of melt would have been present. The overall population density of the microcline would have been reduced by the coarsening process.

Any preferential orientation of the initial, small K-feldspar crystals produced by early flow of the magma would be maintained in the final megacrysts, even if magmatic deformation had ceased. However, grain rotations during coarsening may reduce the quality (intensity), but not the direction, of the mineral fabric (Higgins 1998).

Migration and crystallization of the interstitial melt over decimetric distances produced nests of crystals because of the positive feedback between coarsening and fluid flow. Coarsening may enhance the permeability of crystal mushes by removing small crystals that may block channels. Increased permeability will lead to focusing of fluid flow and further growth of megacrysts along the channels. The channels formed by these interactions will appear as linear regions and nests of crystals in the two-dimensional surface of the outcrop. Hence, the megacryst-rich zones were open systems. Euhedral zones of inclusions in the megacrysts may represent times when growth rate was higher due to greater fluid flow and hence transport of crystal nutrients.

Chadocrysts in mafic rocks preserve early textures (Mathison 1987; Higgins 1991). If the Cathedral Peak Granodiorite megacrysts are indeed phenocrysts then the included grains of plagioclase, mafic minerals and quartz must be chadocrysts. The important size difference between the chadocrysts and the groundmass minerals indicates that all the minerals in the groundmass, except microcline, must also have grown. The small quantity of crystals in the core of the megacrysts shows that coarsening must have started at low crystal contents, of the order of $5-10 \%$ (some early mafic minerals were swept aside by the megacryst and not incorporated).

The groundmass microcline crystals form a population distinct from the megacrysts both on the basis of their shape and size distributions (Figs 4, 5, 7). The groundmass microcline crystals cannot be a residual early population of crystals as such crystals would have been dissolved during coarsening. Straight-line CSDs like those seen in the groundmass have been observed in many volcanic rocks (Cashman 1990) and are interpreted to indicate either continuous flow, steadystate crystallization or batch crystallization in an environment of linearly increasing undercooling (Marsh 1988, 1998). Although studies of plutonic rock CSDs are rare, and hence few straight-line CSDs have been recorded, the batch crystallization model could readily be applied to the groundmass microcline. Indeed the CSDs of plagioclase in plutonic rocks have broadly similar slopes and intercepts to the groundmass microcline (Higgins 1991, 1998). Such an environment of increasing undercooling occurred at the end of the intrusive cycle of the Tuolumne Suite (Fig. 9c). It may have been related to the eruption of the Johnson Creek porphyry-loss of confining pressure may have been accompanied by loss of water from the magma. The resulting increase in liquidus temperature would have increased the undercooling.

Megacrysts occur in many other granitoids, but are also lacking in many chemically similar plutons. The model proposed here necessitates a period of low undercooling to develop the megacrysts. If this was not present then an equigranular rock would have formed. Hence, it is the cooling environment, rather than the chemical composition, that controls the development of megacrysts.

\section{Conclusions}

It has been commonly stated that igneous rock textures are produced by the interplay of 
nucleation and growth of crystals (i.e. Swanson 1977), but in the Cathedral Peak Granodiorite, solution of crystals was equally important. Three steps were necessary to produce the textures observed in the Cathedral Peak granodiorite. (1) Initial nucleation and growth in an environment of increasing undercooling, probably associated with the ascent of the magma. (2) Reduction of undercooling following emplacement of the Cathedral Peak Granodiorite into warm host rocks. Small crystals of K-feldspar were dissolved and larger crystals grew, reducing the overall population density of $\mathrm{K}$-feldspar in the Cathedral Peak Granodiorite and the adjacent parts of the Half-Dome Granodiorite. K-feldspar coarsened more than the other crystals because it was maintained close to its liquidus for a longer period. (3) Resumption of undercooling at the end of the intrusive cycle. Early orientation fabrics produced during the first phase will be conserved in the megacrysts, even if magma movement has ceased. Other important points are as follows. (1) Although the textural coarsening process proposed here is firmly igneous in origin, it has similarities with some metasomatic processes. The megacrysts grew in a normal igneous fashion from a silicate melt at high temperature and are, indeed, phenocrysts. However, the process envisaged here involves both solution of crystals and transport of material in open systems, which are both features of metasomatic systems. (2) The low population density of the megacrysts is not due to "nucleation difficulties' but is a result of solution of most of the early formed crystals. (3) Coarsening started at low crystal contents-5-10\%. (4) The nests and linear zones of megacrysts are 'fossil' fluid channels, produced by the positive feedback between permeability and coarsening. (5) Coarsening and 'openness' of magmatic systems are independent. That is, in some areas crystals can grow very large, but their volumetric abundance will not change. Elsewhere, the abundance of crystals will increase concomitantly with coarsening. (6) Megacrysts are developed in granitoids that have had a particular cooling history. Undercooling must be buffered near the liquidus of $\mathrm{K}$-feldspar for a long period so that the texture can coarsen.

I would like to thank W. Hildreth for suggesting this project. E. Sawyer, M. Roberts, D. Vanko, E. Ferre and an anonymous reviewer made helpful suggestions. I completed this project during a sabbatical at Université Blaise-Pascal, Clermont-Ferrand, France. This project was funded by the Natural Science and Engineering Research Council of Canada.

\section{References}

Bateman, P. C. \& Chappell, B. W. 1979. Crystallisation, fractionation, and solidification of the Tuolumne Intrusive series, Yosemite National Park, California. Geological Society of America Bulletin, 90, 465-482.

Boudreau, A. E. 1987. Pattern forming during crystallisation and the formation of fine-scale layering. In: PARSONS, I. (ed.) Origins of igneous layering. D. Reidel, Dordrecht, 453-471.

Cashman, K. V. 1990. Textural constraints on the kinetics of crystallization of igneous rocks. In: Nicholls, J. \& Russell, J. K. (eds) Modern methods of igneous petrology: understanding magmatic processes. Mineralogical Society of America, 259-314.

— \& FerRy, J. M. 1988. Crystal size distribution (CSD) in rocks and the kinetics and dynamics of crystallization III. Metamorphic crystallization. Contributions to Mineralogy and Petrology, 99, 410-415.

— \& Marsh, B. D. 1988. Crystal size distribution (CSD) in rocks and the kinetics and dynamics of crystallisation II. Makaopuhi lava lake. Contributions to Mineralogy and Petrology, 99, 292-305.

Collins, L. G. 1988. Hydrothermal differentiation and myrmekite; a clue to many geologic puzzles. Theophrastus Publications, Athens, Greece.

DeHOFF, R. T. 1991. A geometrically general theory of diffusion controlled coarsening. Acta Metallurgica et Materialia, 39, 2349-2360.

Dickson, F. W. 1996. Porphyroblasts of barium-zoned K-feldspar and quartz, Papoose Flat, Inyo Mountains, California, genesis and exploration implications. In: CoYner, A. R. \& FAHEY, P. L. (eds) Geology and Ore Deposits of the Cordillera. Geological Society of Nevada Symposium Proceedings, Reno/Sparks, Nevada, 909-924.

FENN, P. M. 1977. The nucleation and growth of alkalifeldspars from hydrous melts. Canadian Mineralogist, 15, 135-161.

Higgins, M. D. 1991. The origin of laminated and massive anorthosite, Sept Iles intrusion, Quebec, Canada. Contributions to Mineralogy and Petrology, 106, 340-354.

- 1998. Origin of anorthosite by textural coarsening: Quantitative measurements of a natural sequence of textural development. Journal of Petrology, 39, 1307-1325.

Hutchison, C. S. 1974. Laboratory handbook of petrographic techniques. John Wiley \& Sons.

KerRick, D. M. 1969. K-feldspar megacrysts from a porphyritic quartz monzonite, central Sierra Nevada, California. American Mineralogist, 54, 839-848.

Lifshitz, I. M. \& Slyozov, V. V. 1961. The kinetics of precipitation from supersaturated solid solutions. Journal of Physics and Chemistry of Solids, 19, 35-50.

MARsh, B. 1988. Crystal size distribution (CSD) in rocks and the kinetics and dynamics of crystallization I. Theory. Contributions to Mineralogy and Petrology, 99, 277-291. 
MARsh, B. D. 1998. On the interpretation of Crystal Size Distributions in magmatic systems. Journal of Petrology, 39, 553-600.

Mathison, C. I. 1987. Pyroxene oikocrysts in troctolitic cumulates-evidence for supercooled crystallisation and postcumulus modification. Contributions to Mineralogy and Petrology, 97, 228-236.

Naney, M. T. 1983. Phase equilibria of rock-forming ferromagnesian silicates in granitic systems. American Journal of Science, 283, 993-1033.

Randolf, A. D. \& LARSON, M. A. 1971. Theory of particulate processes. Academic Press, New York.
ResminI, R. G. 1993. Dynamics of magma in the crust: A study using crystal size distribution. $\mathrm{PhD}$, Johns Hopkins University.

ROYET, J.-P. 1991. Stereology: A method for analysing images. Progress in Neurobiology, 37, 433-474.

Swanson, S. E. 1977. Relation of nucleation and crystal-growth rate to the development of granitic textures. American Mineralogist, 62, 966-978.

VERNON, R. H. 1986. K-feldspar megacrysts in granites-Phenocrysts not porphyroblasts. EarthScience Reviews, 23, 1-63.

VoorheEs, P. W. 1992. Ostwald ripening of two-phase mixtures. Annual Review of Materials Science, 22, 197-215. 